\section{Transnasal Percutaneous Endoscopic Gastrostomy Using a Standard-Diameter Gastroscope (9.8 $\mathrm{mm}$ )}

Transoral percutaneous endoscopic gastrostomy (PEG) is not possible in some patients due to difficulty in opening the mouth (e.g., in patients with head and neck cancers, oral submucous fibrosis, dental misalignment, and intermaxillary fixation). Transnasal endoscopy has been used for diagnostic upper gastrointestinal endoscopy and for placement of enteral feeding tubes $[1,2]$. However, the small diameter of the accessory channel in transnasal instruments $(2 \mathrm{~mm})$ limits their use for therapeutic interventions [3]. A study of transnasal percutaneous endoscopic gastrostomy (TN-PEG) using pediatric scopes (with an outer diameter of $7.9 \mathrm{~mm}$ ) reported failure of the method in three of six patients [4]. TN-PEG using standard-diameter endoscopes has been reported [5].

We prospectively studied the feasibility of TN-PEG using a standard-diameter endoscope in six patients (five men, one woman; median age 50). Transoral PEG was not possible in these patients due to dental misalignment in four cases, and due to postoperative anatomy in patients who had undergone head and neck surgery in two cases. The nostrils were inspected to identify the more patent nostril and to determine whether a deviated nasal septum was present. The wider nostril was sprayed with $10 \%$ lidocaine, followed by the application of lubricant jelly. After intravenous sedation with midazolam $2 \mathrm{mg}$, an Olympus GIF-Q140 instrument (outer diameter $9.8 \mathrm{~mm}$ ) was introduced through the nostril and was negotiated through the nasal cavity under vision. Pushing was used to advance the scope if the lumen was slightly narrow. Once the nasopharynx had been successfully negotiated, the subsequent steps were carried out in the same way as in transoral percutaneous endoscopic gastrostomy. A 20-Fr Bard tube with markings was placed using the pull technique. The tapered and stiff dilating portion of this tube is $7 \mathrm{~cm}$ long and requires gentle and cautious pulling.

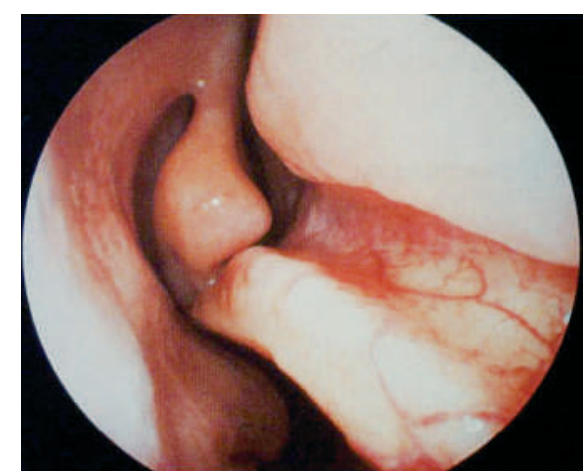

Figure 1 The extreme deviation of nasal septum in this case means that it is inappropriate to attempt transnasal percutaneous endoscopic gastrostomy.

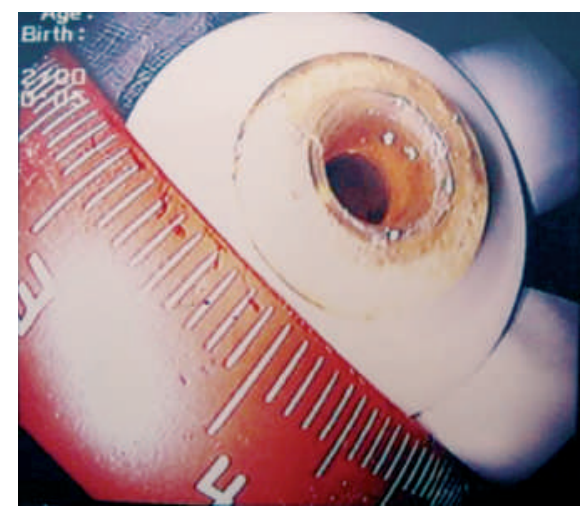

Figure 2 The gastrostomy tube shown here has a disk-like hard internal bolster, which is not suitable for transnasal percutaneous endoscopic gastrostomy.

The procedure was successful in five of the patients; the one failure was due to the presence of a narrow nasal cavity. Complications included mild epistaxis in two patients. We then studied five patients (four men and one women) using GIF 160 (OD $8.6 \mathrm{~mm}$ ) and TN-PEG was successful in all.

TN-PEG is therefore feasible in selected patients. Important factors for success are patency of the nasopharynx (Figure $\mathbf{1})$, the diameter of the endoscope, and the characteristics of the PEG tube used (Figure 2).

D. Desai', A. Joshi', P. Abraham', M. Chawla ${ }^{1}$, A. Sonsale ${ }^{2}$

${ }^{1}$ Division of Gastroenterology, P.D. Hinduja National Hospital and Medical Research Center, Mumbai, India ${ }^{2}$ Division of Otorhinolaryngology, P.D. Hinduja National Hospital and Medical Research Center, Mumbai, India.

\section{References}

${ }^{1}$ Kulling D, Bauerfeind P, Fried M. Transnasal versus transoral endoscopy for placement of nasoenteral feeding tubes in critically ill patients. Gastrointest Endosc 2000; 52: 506-510

2 Dranoff JA, Angood PJ, Topazian M. Transnasal endoscopy for enteral feeding tube placement in critically ill patients. Am J Gastroenterol 1999; 94: 2902-2904

${ }^{3}$ Sorbi D, Chak A. Unsedated EGD. Gastrointest Endosc 2003; 58: $102-110$

${ }^{4}$ Lustberg AM, Darwin PE. A pilot study of transnasal percutaneous endoscopic gastrostomy [letter]. Am J Gastroenterol 2002; 97: 1273 - 1274

${ }^{5}$ Taller A, Horvath E, Elias Let al. Technical modification for improving the success rate of PEG tube placement in patients with head and neck cancer. Gastrointest Endosc 2001; 54: 633-636

\section{Corresponding Author}

\section{Desai, M.D.}

P.D. Hinduja National Hospital and Medical Research Center

Veer Savarkar Marg, Mahim

Mumbai 400016

India

Fax: $\quad+91-22-24440425$

E-mail: desaid@vsnl.com 